\title{
WAVEFRONT GUIDED T-PRK AS ATREATMENT OF HIGHER ORDER ABERRATIONS AFTER LASIK
}

Abdelhamid Shaker Elhofi, Tamer Hamdy Masoud, Mohamed Essam Abdo

Department of ophthalmology, Faculty of Medicine, Alexandria University.

\section{INTRODUCTION}

Laser in situ keratomileusis (LASIK) is the most frequently performed corneal refractive procedure.

LASIK can reduce refractive error and improve uncorrected visual acuity, but several problems still must be resolved regarding postoperative visual function.

The retreatment rates for residual overcorrection, undercorrection, induced astigmatism and visual dysfunction due to higher order aberrations following LASIK ranges widely from $5 \%$ to $37.9 \%$.

The most commonly used technique for LASIK retreatment is flap relift or flap recutting. However, complications such as buttonhole creation, post-LASIK dry eye syndrome, thin residual stromal bed, and the inability to identify the flap edge can limit surgical options for retreatment

In addition, relifting an old flap increases the risk of epithelial ingrowth, flap tear striae, and diffuse lamellar keratitis. To avoid these complications, photorefractive keratectomy (PRK) could be used

Transepithelial PRK (tPRK) is a technique where the epithelium is removed using excimer laser PTK prior to application of the stromal refractive treatment.

More recently, a novel treatment modality utilizing excimer epithelial removal using a population-based epithelial profile rather than PTK epithelial removal has become available on the SCHWIND Amaris platform termed transepithelial all surface lase ablation (ASLA).

\section{AMM OF THE WORK}

The aim of this work is assessment of wavefront guided transepithelial PRK for the treatment of higher order aberrations after LASIK.

\section{PATIENTS AND METHODS}

Patients: An interventional prospective study was conducted on 30 eyes with Patients: An interv guided transepithelial PRK.

Inclusion criteria: Patients who complained of diminution of vision \& unsatsifaction of quality of vision after lasik.
Exclusion criteria: Any anterior segment pathology or media opacity,Irregular topography, History of postoperative complications as diffuse lamellar keratitis (DLK), central toxic keratopathy (CTK) and infection in the previous surgery. Any posterior segment pathology that would affect the optic nerve or the retina. METHODS:

All subjects included in the present study were subjected to:

Preoperative:

Full History taking, Complete ophtalmological examination,Visual acuity Full History taking, Complete ophtalmological examination, Visual acuity
(uncorrected and corrected distant visual acuity), Manifest refraction and cycloplegic (uncorrected and corrected distant visual acuity), Man
refraction \& Contrast sensitivity test using CSV 1000.

refraction \& Contrast sensitivity test usin
Corneal topography using 2 devices :

Scheimpflug camera based, i.e, pentacam (WaveLight Oculyzer II)

Combined scheimpflug camera based and placido based, i.e, corneal topographer (Sirius, SCHWIND eye-tech-solutions).

Operative: All treatments were performed using Wavefront guided transepithelial PRK by SCHWIND Amaris 1050RS platform after computerized corneal wavefront data exported from Sirius corneal topographer.

Post operative: Patients were checked 3 months post operative for:

Complete ophtalmological examination, Visual acuity (uncorrected and corrected distant visual acuity), Manifest refraction and cycloplegic refraction, Contrast sensitivity test using CSV 1000

Corneal topography using pentacam (WaveLight Oculyzer II) \& (Sirius, SCHWIND eye-tech-solutions).

\section{RESULTS}

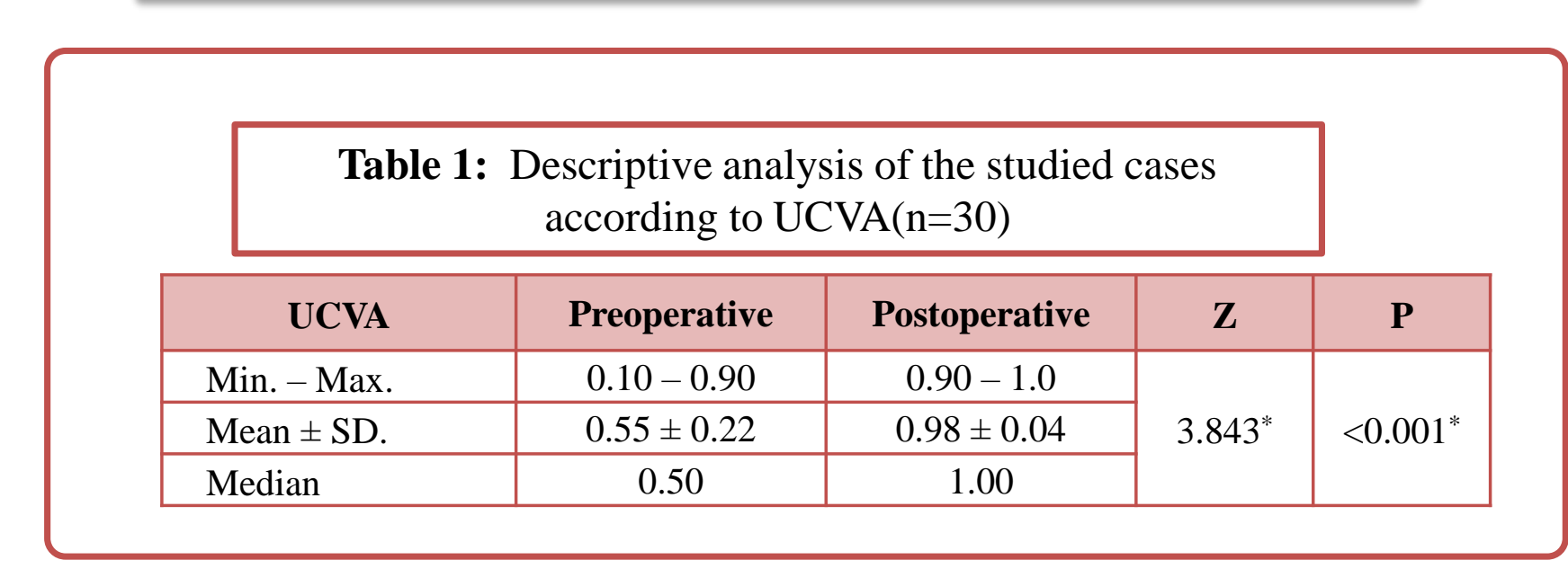

Table 2: Descriptive analysis of the studied cases according to contrast sensetivity $(\mathrm{n}=30)$

\begin{tabular}{|c|c|c|c|c|}
\hline Contrast & Preoperative & Postoperative & $\mathbf{Z}$ & $\mathbf{p}$ \\
\hline $\mathrm{pd}$ & & & & \\
\hline Min. - Max. & $1.17-1.63$ & $1.63-2.08$ & \multirow{3}{*}{$3.835^{*}$} & \multirow{3}{*}{$<0.001^{*}$} \\
\hline Mean \pm SD & $1.47 \pm 0.13$ & $1.91 \pm 0.15$ & & \\
\hline Median & 1.49 & 1.93 & & \\
\hline ccpd & & & & \\
\hline Min. - Max. & $1.38-1.70$ & $1.84-2.29$ & \multirow{3}{*}{$3.832^{*}$} & \multirow{3}{*}{$<0.001^{*}$} \\
\hline Mean \pm SD & $1.49 \pm 0.12$ & $2.12 \pm 0.14$ & & \\
\hline Median & 1.55 & 2.14 & & \\
\hline $2 \mathrm{cpd}$ & & & \multirow{4}{*}{$3.829^{*}$} & \\
\hline Min. - Max. & $0.91-1.40$ & $1.54-1.99$ & & \multirow{3}{*}{$<0.001^{*}$} \\
\hline Mean \pm SD. & $1.13 \pm 0.14$ & $1.74 \pm 0.18$ & & \\
\hline Median & 1.08 & 1.69 & & \\
\hline $18 \mathrm{cpd}$ & & & \multirow{4}{*}{$3.833^{*}$} & \\
\hline Min. - Max. & $0.47-0.81$ & $0.96-1.40$ & & \multirow{3}{*}{$<0.001^{*}$} \\
\hline Mean \pm SD & $0.65 \pm 0.13$ & $1.23 \pm 0.12$ & & \\
\hline Median & 0.64 & 1.25 & & \\
\hline
\end{tabular}

\section{CONCLUSION}

- Many patients were unsatisfied about the quality of vision and had night vision problems after lasik.

- Sirius machine is a good method to measure corneal higher order aberrations

- Contrast sensitivity test is a helping test to assess the quality of vision.

- Wavefront guided T-PRK is safe and effective surgery to treat higher order aberrations.

$$
\begin{gathered}
\text { 20210Alexandria Faculty of Medicine } \\
\text { CC-BY-NC }
\end{gathered}
$$

